\title{
Properties of $\boldsymbol{N}$-maleoylmethionine sulphone, a novel impermeant maleimide, and its use in the selective labelling of the erythrocyte glucose-transport system
}

\author{
S. Jane ROBERTS, Michael J. A. TANNER and Richard M. DENTON \\ Department of Biochemistry, University of Bristol, Bristol BS8 1TD, U.K.
}

(Received 30 December 1981/Accepted 16 April 1982)

1. The synthesis of $N$-maleoylmethionine sulphone (MMS), a membrane-impermeant protein-labelling reagent, is described. Radioactively labelled MMS can be readily prepared at high specific radioactivity from $\left[{ }^{35} \mathrm{~S}\right]$ methionine. 2 . The permeability of the erythrocyte membrane to the reagent was assessed by determining the extent of inactivation of glyceraldehyde 3-phosphate dehydrogenase after treatment of erythrocytes with MMS. Some inactivation of this enzyme was found when high concentrations $(20 \mathrm{~mm})$ of the compound were used, but this could be prevented by pretreatment of the erythrocytes with 4,4'-di-isothiocyanatostilbene-2,2'-disulphonic acid, suggesting that MMS slowly enters the cells via the anion-transport system. 3. Treatment of erythrocytes with $\left[{ }^{35} \mathrm{~S}\right] \mathrm{MMS}$ resulted in the labelling of six major components. Labelling of erythrocyte membranes resulted in the intense labelling of many additional components. 4. MMS inhibited erythrocyte glucose transport. Cytochalasin b protected glucose transport against inactivation by MMS. Labelling experiments on erythrocytes in the presence and in the absence of cytochalasin $b$ showed that the cytochalasin b-protected material was a broad band in the band-4.5 region.

Abbott \& Schachter (1976) have described the synthesis of a series of membrane-impermeant maleimide reagents. One of these, glutathionemaleimide, was used to identify an exofacial component of the human erythrocyte hexose-transport mechanism by employing a differential labelling technique with cytochalasin $b$ as a masking agent (Batt et al., 1976). This component migrated as a broad band (in the band-4.5 region) between bands 4.2 and 5 (nomenclature of Steck, 1974) on sodium dodecyl sulphate / polyacrylamide-gel electrophoresis of labelled erythrocyte membranes. The band-4.5 region contains several different protein components.

Other workers have used cytochalasin b protection against labelling with 1-fluoro-2,4-dinitrobenzene in protein-depleted erythrocyte-membrane vesicles, and have also shown selective labelling of a broad band in the band-4.5 region (Leinhard et al., 1977). The same material has been shown to be the cytochalasin b-binding component of the human

Abbreviation used: MMS, $N$-maleoylmethionine sulphone. erythrocyte membrane (Kasahara \& Hinkle, 1977; Kahlenberg \& Zala, 1977; Baldwin et al., 1979).

In the present paper we describe the synthesis and properties of a new membrane-impermeant maleimide, $N$-maleoylmethionine sulphone (MMS). This labelling agent may be synthesized simply from ${ }^{[35}$ S]methionine to much higher specific radioactivities than the membrane-impermeant maleimides that have been previously reported. MMS irreversibly inhibits glucose influx into human erythrocytes, and cytochalasin $b$ will protect against this inhibition. Differential labelling experiments on erythrocytes with cytochalasin $b$ as a masking agent suggest that the reagent reacts with a component in the band -4.5 region, which is associated with erythrocyte glucose transport. These studies suggest that MMS should be of general utility as a membrane-impermeant thiol-labelling reagent.

\section{Methods}

Synthesis of $N$-maleoylmethionine sulphone

$N$-Maleoylmethionine was synthesized by the method of Rich et al. (1975), from $5.96 \mathrm{~g}$ of methionine and $3.92 \mathrm{~g}$ of maleic anhydride, except 
that the maleamic acid was not recrystallized before the reflux step. As the final step ethyl acetate was removed on the rotary evaporator, to yield a brown oil.

Performic acid was prepared by treating $237.5 \mathrm{ml}$ of formic acid with $12.5 \mathrm{ml}$ of $30 \%(\mathrm{w} / \mathrm{v}) \mathrm{H}_{2} \mathrm{O}_{2}$. After standing for $2 \mathrm{~h}$, this was added to the maleimide residue and allowed to react for $90 \mathrm{~min}$. The volume was decreased to about $10 \mathrm{ml}$ on the rotary evaporator and the orange oil was left overnight at $5^{\circ} \mathrm{C}$. The MMS crystals were filtered and washed with ice-cold diethyl ether. The filtrate was seeded with MMS crystals, left to stand in the cold and the process repeated. A typical preparation gave three harvests of crystals, which were pooled and recrystallized from formic acid to give $1.42 \mathrm{~g}$ ( $14 \%$ yield) of MMS, m.p. $161^{\circ} \mathrm{C}$ (uncorrected).

MMS was stored under vacuum at $-20^{\circ} \mathrm{C}$. The melting point was unchanged under these conditions after 3 months. Elementary analysis gave: $\mathrm{C}, \mathbf{4 1 . 2}$; $\mathrm{H}, 3.9 ; \mathrm{N}, 5.2 ; \mathrm{S}, 12.4$; calculated for $\mathrm{C}_{9} \mathrm{H}_{11} \mathrm{NO}_{6} \mathrm{~S}$ : $\mathrm{C}, 41.4 ; \mathrm{H}, 4.2 ; \mathrm{N}, 5.4 ; \mathrm{S}, 12.3 \%$. Spectrophotometric titration of the product against 2-mercaptoethanol in $0.1 \mathrm{M}$-sodium phosphate buffer, $\mathrm{pH} 8.0$, with the use of 5,5'-dithiobis-(2-nitrobenzoic acid) to assay free thiol groups, yielded an apparent molecular weight of 263.6 (261.2 calculated molecular weight). T.l.c. of the product on cellulose plates (Merck 5577) with methanol/acetic acid $(19: 1, \mathrm{v} / \mathrm{v})$ gave a single component $\left(R_{F} 0.68\right)$ when the plates were stained with $0.1 \%$ cysteine hydrochloride, followed by 5,5'-dithiobis-(2-nitrobenzoic acid) $(4 \mathrm{mg} / \mathrm{ml})$ in $100 \mathrm{~mm}$-sodium phosphate buffer, pH 8.0.

\section{Preparation of $\mathrm{N}$-maleoylmethionine $\left[{ }^{35} \mathrm{~S}\right]$ sulphone}

$\left.{ }^{\left[{ }^{35}\right.} \mathrm{S}\right]$ Methionine was prepared by the method of Bretscher \& Smith (1972). A $1 \mathrm{mCi}$ portion of the $\left[{ }^{35} \mathrm{~S}\right]$ methionine $(40 \mathrm{Ci} / \mathrm{mmol})$ was freeze-dried in a glass hydrolysis tube. Then $5 \mathrm{mg}$ of maleic anhydride in $0.5 \mathrm{ml}$ of acetic acid was added. The mixture was left for $30 \mathrm{~min}$ and then dried down over $\mathrm{P}_{2} \mathrm{O}_{5}$ and $\mathrm{NaOH}$. Then $0.5 \mathrm{ml}$ of toluene and $1 \mu \mathrm{l}$ of triethylamine were added, and the tube was sealed under vacuum and then heated at $110^{\circ} \mathrm{C}$ for $1 \mathrm{~h}$. The tube was opened and the contents were dried down. Next $0.5 \mathrm{ml}$ of performic acid was added, and after $1 \mathrm{~h}$ this was removed under vacuum. The tube contents were dissolved in $25 \mu \mathrm{l}$ of water and streaked across the origin of a cellulose t.l.c. plate (Merck 5577). The tube was rinsed with two further $25 \mu \mathrm{l}$ volumes of water, and these washings were also applied to the plate. The plate was developed in methanol/acetic acid $(19: 1, \mathrm{v} / \mathrm{v})$ and then radioautographed for $5 \mathrm{~min}$. The major radioactive band $\left(R_{F} 0.68\right)$ was scraped off the plate, and the adsorbent was collected by suction into a small glass tube containing a sintered-glass frit. The product was eluted from the adsorbent by four $250 \mu \mathrm{l}$ volumes of water. A typical radioactivity yield of [ $\left.{ }^{35} \mathrm{~S}\right] \mathrm{MMS}$ was $400 \mu \mathrm{Ci}(40 \%)$. Appropriate amounts of carrier MMS were added and the solution was freeze-dried.

\section{Assay of glyceraldehyde 3-phosphate dehydrogen- ase activity}

Human erythrocytes were washed three times with $0.15 \mathrm{M}-\mathrm{NaCl}$ and twice with $0.1 \mathrm{M}$-sodium phosphate buffer, pH 8.0. The cells were then incubated with $4 \mathrm{vol}$. of various concentrations of $N$-ethylmaleimide or MMS in $0.1 \mathrm{M}$-sodium phosphate buffer, $\mathrm{pH} 8.0$, with or without $0.1 \%$ Triton $\mathrm{X}-100$ (Sigma Chemical Co.) for $30 \mathrm{~min}$ at $37^{\circ} \mathrm{C}$. To each of the tubes containing detergent was added $30 \mu \mathrm{l}$ of $10 \%(\mathrm{v} / \mathrm{v}) 2$-mercaptoethanol in $0.1 \mathrm{M}$ sodium phosphate buffer, pH 8.0. The cells in the remaining tubes were washed once with $40 \mathrm{mM}^{-}$ 2-mercaptoethanol in $0.1 \mathrm{M}$-sodium phosphate buffer, $\mathrm{pH} 8.0$, then twice in $0.1 \mathrm{M}$-sodium phosphate buffer, pH 8.0. Glyceraldehyde 3-phosphate dehydrogenase activity was assayed by a fluorimetric method (Boxer et al., 1974) in the presence of $0.1 \%$ Triton X-100.

\section{Assay of glucose-transport activity}

Human erythrocytes were washed as described above. Half the sample was incubated with 2 vol. of $0.1 \mathrm{M}$-sodium phosphate buffer, $\mathrm{pH} 8.0$, containing $1 \%(\mathrm{v} / \mathrm{v})$ ethanol, and the other half with the above solution containing $20 \mu \mathrm{M}$-cytochalasin b (Sigma Chemical Co.). After $10 \mathrm{~min}$ at $37^{\circ} \mathrm{C}$ each sample was divided and one half was made $10 \mathrm{~mm}$ in MMS. After $30 \mathrm{~min}$ at $37^{\circ} \mathrm{C}$ the cells were washed once with $20 \mathrm{mM}$-2-mercaptoethanol in $0.1 \mathrm{M}$-sodium phosphate buffer, $\mathrm{pH} 8.0$, then four times with $0.3 \mathrm{M}$-triethanolamine/citrate buffer, $\mathrm{pH}$ 7.5. A sample of the control cells was made $20 \mu \mathrm{M}$ in cytochalasin $b$ and $1 \%$ in ethanol and was incubated for $10 \mathrm{~min}$ at $37^{\circ} \mathrm{C}$.

The cells were assayed for glucose-transport activity at $10^{\circ} \mathrm{C}$. The assay buffer was $0.3 \mathrm{M}$ triethanolamine/citrate, $\mathrm{pH} 7.5$. To $0.5 \mathrm{ml}$ of $\left[{ }^{3} \mathrm{H}\right]-$ sucrose (Amersham International) $(100 \mu \mathrm{g} / \mathrm{ml}$, $5 \mu \mathrm{Ci} / \mathrm{ml}$ ) was added $0.1 \mathrm{ml}$ of packed erythrocytes for the determination of extracellular volume. The suspension was allowed to equilibrate with shaking for $2 \mathrm{~min}$ at $10^{\circ} \mathrm{C}$. Then $0.1 \mathrm{ml}$ of $70 \mathrm{~mm}-\left[{ }^{14} \mathrm{C}\right]-$ glucose (Amersham International) $(5 \mu \mathrm{Ci} / \mathrm{ml})$ was added to initiate transport, and at intervals $0.1 \mathrm{ml}$ samples were quenched into $0.5 \mathrm{ml}$ of ice-cold $2 \%$ $(\mathrm{w} / \mathrm{v}) \mathrm{NaCl}$ containing $2 \mathrm{mM}-\mathrm{HgCl}_{2}$ and $1.25 \mathrm{mM}-\mathrm{KI}$ (Levine \& Stein, 1966). The cells were centrifuged, and $0.2 \mathrm{ml}$ samples of the supernatant were added to $0.2 \mathrm{ml}$ of $10 \%(\mathrm{w} / \mathrm{v})$ trichloroacetic acid. The erythrocytes were lysed in $0.2 \mathrm{ml}$ of ice-cold water, 
then $0.2 \mathrm{ml}$ of $10 \%$ trichloroacetic acid was added. Both supernatant and pellet samples were centrifuged to remove precipitated protein, and $0.2 \mathrm{ml}$ portions were each dispersed in $10 \mathrm{ml}$ of scintillant [mixture of $2 \mathrm{~kg}$ of naphthalene, 15 litres of toluene, 10 litres of methoxyethanol and $100 \mathrm{~g}$ of $5-(4-$ biphenylyl)-2-(4-t-butylphenyl)-1-oxa-3,4-diazole]. Radioactivities of samples were counted on channel 9 of an Isocap 300 scintillation counter, and the counts were separated and quench-corrected on a Hewlett-Packard 9821A computer by using a program written by Dr. A. P. Halestrap.

\section{Selective labelling of the erythrocyte glucose trans- porter}

Freshly drawn blood was taken, with EDTA $(1 \mathrm{mg} / \mathrm{ml})$ as an anticoagulant. The protocol for treatment of the washed cells with ethanol and either MMS or cytochalasin b, or both, was the same as that described above for the glucose-transport experiments. After being washed with $20 \mathrm{~mm}-2$ mercaptoethanol, the cells were washed four times with $0.1 \mathrm{M}$-sodium phosphate buffer, $\mathrm{pH}$ 8.0. Each sample was then divided; to one half was added 2 vol. of $0.1 \mathrm{M}$-sodium phosphate buffer, $\mathrm{pH} 8.0$, containing $1 \%(\mathrm{v} / \mathrm{v})$ ethanol, and to the other half was added 2 vol. of $0.1 \mathrm{M}$-sodium phosphate buffer, pH 8.0, containing $1 \%$ ethanol and $20 \mu \mathrm{M}$-cytochalasin b. After $10 \mathrm{~min}$ at $37^{\circ} \mathrm{C}$ the cells were centrifuged, and $50 \mu \mathrm{l}$ portions of packed erythrocytes were transferred to tubes containing $45 \mu \mathrm{Ci}$ of $\left[{ }^{35} \mathrm{~S}\right] \mathrm{MMS}$ $(0.45 \mathrm{Ci} / \mathrm{mmol}$; final extracellular concentration $8 \mathrm{~mm}$ ). After $30 \mathrm{~min}$ at $37^{\circ} \mathrm{C}$ the cells were resuspended in $20 \mathrm{mM}$-2-mercaptoethanol in $0.1 \mathrm{M}$-sodium phosphate buffer, $\mathrm{pH} 8.0$, and re-centrifuged. The erythrocytes were washed twice more in $0.1 \mathrm{M}$ sodium phosphate buffer, $\mathrm{pH} 8.0$, and then lysed in ice-cold $5 \mathrm{~mm}$-sodium phosphate buffer, $\mathrm{pH}$ 8.0. The membranes were washed once with ice-cold $5 \mathrm{mM}$ sodium phosphate buffer, $\mathrm{pH} 8.0$, once with ice-cold $0.1 \mathrm{M}-\mathrm{NaOH}$ containing $5 \mathrm{~mm}-2$-mercaptoethanol, then twice in ice-cold $5 \mathrm{~mm}$-sodium phosphate buffer, $\mathrm{pH}$ 8.0, and then dissolved for sodium dodecyl sulphate/polyacrylamide-gel electrophoresis, by the method of Laemmli (1970).

\section{Labelling of erythrocyte membrane proteins}

Packed washed human erythrocytes $(0.1 \mathrm{ml})$ were labelled in tubes each containing $30 \mu \mathrm{Ci}$ of freezedried ${ }^{33}$ S $]$ MMS at different specific radioactivities. After $10 \mathrm{~min}$ at room temperature the cells were washed once with $20 \mathrm{~mm}$-2-mercaptoethanol in $0.1 \mathrm{M}$-sodium phosphate buffer, $\mathrm{pH} 8.0$, then twice with iso-osmotic sodium phosphate buffer, $\mathrm{pH}$ 7.4. Membranes were prepared and washed with $0.1 \mathrm{M}$ $\mathrm{NaOH}$ containing $5 \mathrm{mM}$-2-mercaptoethanol followed by 5 mM-sodium phosphate buffer, $\mathrm{pH} 8.0$, before being dissolved for sodium dodecyl sulphate/polyacrylamide-gel electrophoresis.
Erythrocyte 'ghosts' were labelled as follows. The membranes were washed once with $5 \mathrm{mM}$-sodium phosphate buffer, $\mathrm{pH} 8.0$, and then suspended in an equal volume of $0.1 \mathrm{M}$-sodium phosphate buffer, $\mathrm{pH}$ 8.0. Portions $(0.1 \mathrm{ml})$ of this suspension were transferred to tubes each containing $30 \mu \mathrm{Ci}$ of freeze-dried ${ }^{[35}$ S]MMS at various specific radioactivities. After $10 \mathrm{~min}$ at room temperature the membranes were stripped with ice-cold $0.1 \mathrm{M}-\mathrm{NaOH}$ containing $5 \mathrm{mM}-2$-mercaptoethanol and prepared for electrophoresis as before.

\section{Results and discussion}

Glyceraldehyde 3-phosphate dehydrogenase is located at the cytoplasmic surface of the erythrocyte membrane. At $200 \mu \mathrm{M}$ MMS completely inhibited the glyceraldehyde 3-phosphate dehydrogenase activity of erythrocytes dissolved with Triton X-100 (Fig. 1). When intact erythrocytes were treated with up to $5 \mathrm{mM}$-MMS essentially all the glyceraldehyde 3-phosphate dehydrogenase activity remained (Fig. 1). In contrast, treatment of intact erythrocytes with $2 \mathrm{mM}-\mathrm{N}$-ethylmaleimide completely abolished glyceraldehyde 3-phosphate dehydrogenase activity (Fig. 1). When erythrocytes were treated with higher concentrations of MMS (20 mM) some inactivation $(40 \%)$ of glyceraldehyde 3-phosphate dehydrogenase occurred. It seemed likely that under these conditions MMS might slowly enter the cell via the membrane transporting systems mediated either by the anion-transporting protein (band 3; Cabantchik \& Rothstein, 1974) or by the transporter for small carboxylate anions (Halestrap, 1976). At $20 \mu \mathrm{M} \mathrm{4,4'-di-isothiocyanato-}$ stilbene-2,2'-disulphonic acid completely blocks anion transport via the band-3 protein, but does not

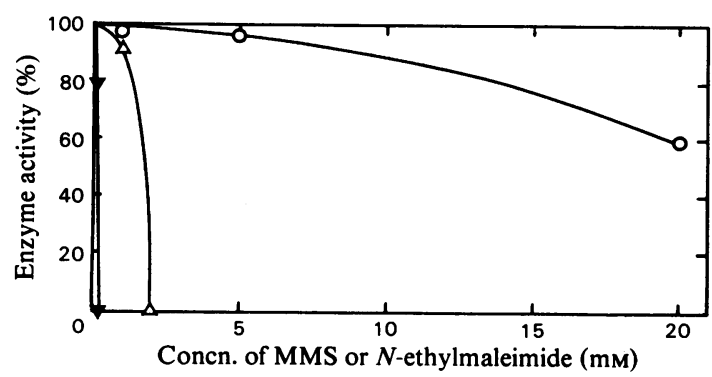

Fig. 1. Glyceraldehyde 3-phosphate dehydrogenase activity of erythrocytes treated with MMS

The cells were treated as indicated and the remaining enzyme activity was measured as described in the Methods section. O, Erythrocytes treated with MMS; $\Delta$, erythrocytes treated with $N$-ethylmaleimide; $\nabla$, erythrocytes treated with Triton X-100 and MMS. 


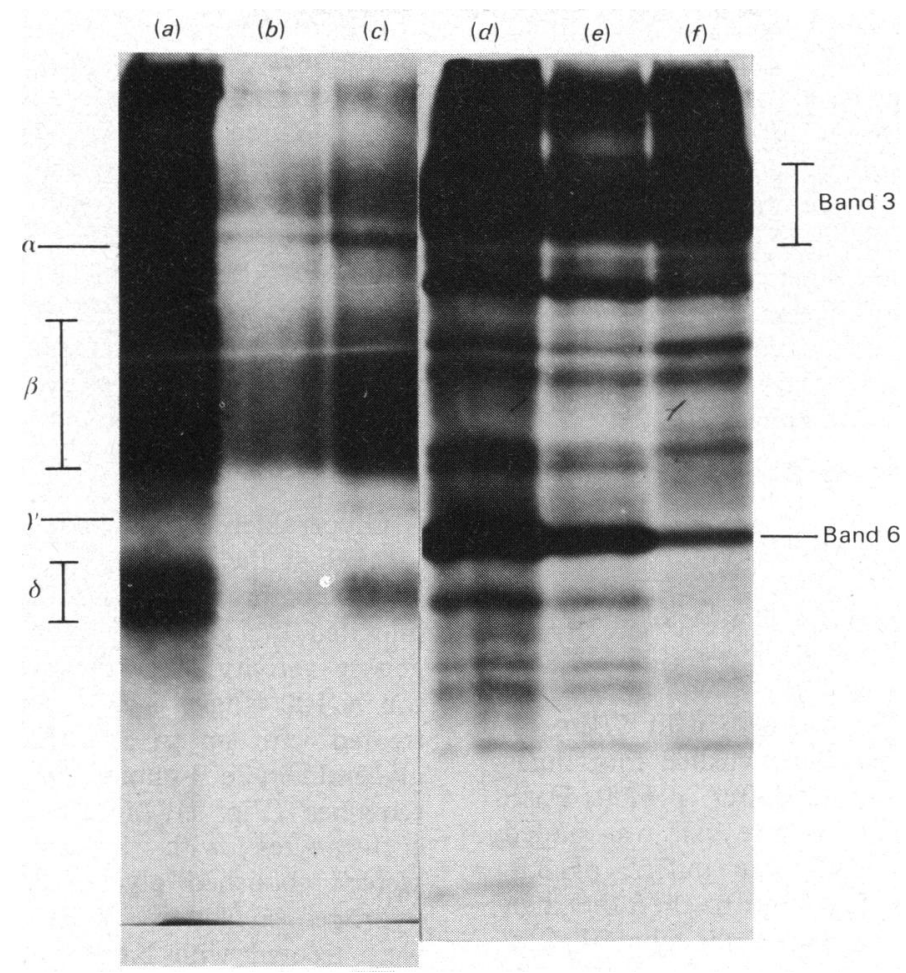

Fig. 2. Labelling of erythrocytes and erythrocyte membranes by $\left[{ }^{35} S\right] M M S$

Intact erythrocytes or erythrocyte 'ghosts' were labelled with $\left[{ }^{35} S\right] M M S$ at different specific radioactivities and concentrations as described in the Methods section. In the case of intact erythrocytes the extracellular space was measured by using $\left[{ }^{3} \mathrm{H}\right]$ sucrose, and yielded a value of $27 \%$ for packed washed erythrocytes. After electrophoresis on sodium dodecyl sulphate/polyacrylamide gels containing 10\% acrylamide (Laemmli, 1970), the gels were prepared for fluorography by the method of Chamberlain (1979) and radioautographs were prepared after exposure at $-70^{\circ} \mathrm{C}$. $(a)-(c)$ Membranes from intact erythrocytes treated wtih [ $\left.{ }^{35} \mathrm{~S}\right] \mathrm{MMS}$ at the concentrations and specific radioactivities indicated: (a) $37 \mu \mathrm{M}, 30 \mathrm{Ci} / \mathrm{mmol}$; (b) $370 \mu \mathrm{M}, 3 \mathrm{Ci} / \mathrm{mmol}$; (c) $3.7 \mathrm{mM}, 0.3 \mathrm{Ci} / \mathrm{mmol}$. (d) $-(f)$ Erythrocyte 'ghosts' labelled with [ $\left.{ }^{35} \mathrm{~S}\right] \mathrm{MMS}$ at the concentration and specific radioactivity indicated: $(d) 10 \mu \mathrm{M}, 30 \mathrm{Ci} / \mathrm{mmol} ;(e) 100 \mu \mathrm{M}$, $3 \mathrm{Ci} / \mathrm{mmol} ;(f) 1 \mathrm{~mm}, 0.3 \mathrm{Ci} / \mathrm{mmol}$.

block transport through the carboxylate transporter. When intact erythrocytes were incubated with $20 \mathrm{mM}-\mathrm{MMS}$ in the presence of $20 \mu \mathrm{M}-$ 4,4'-di-isothiocyanatostilbene-2,2'-disulphonic acid, $94.9 \pm 4.4 \%$ (mean \pm S.D., $n=3$ ) of the original glyceraldehyde 3-phosphate dehydrogenase activity remained, suggesting that the low permeability of the membrane to MMS at high concentrations of the reagent is mediated by the erythrocyte aniontransport protein.

Fig. 2 shows radioautographs of sodium dodecyl sulphate/polyacrylamide-gel electrophoretograms of intact erythrocytes and erythrocyte membranes labelled with $\left.{ }^{35} \mathrm{~S}\right] \mathrm{MMS}$. The striking difference in patterns obtained with intact cells and with leaky membranes provides further evidence that MMS is an impermeant reagent. Abbott \& Schachter (1976) reported that only $3 \%$ of the total erythrocyte membrane thiol groups are exofacial, whereas $57 \%$ are located at the cytoplasmic face of the membrane. This accounts for the more intense labelling observed with leaky erythrocyte 'ghosts' than with whole cells.

Exo- and endo-facial labelling of the erythrocyte membrane with $\left[{ }^{35} S\right] M M S$

Abbott \& Schachter (1976) found that glutathione-maleimide, when applied to the exofacial surface of the erythrocyte membrane, labelled four components that were resolved by sodium dodecyl sulphate/polyacrylamide-gel electrophoresis. They denoted these $\alpha$ (apparent molecular weight 89000), $\beta$ (40000 to 70000), $\gamma(36000)$ and $\delta(32000)$. When erythrocytes were treated with $\left[{ }^{35} \mathrm{~S}\right] \mathrm{MMS}$ 
(Figs. $2 a, 2 b$ and $2 c$ ), labelling was observed in six major components, two sharp and four broad bands. Additional bands seen at the highest specific radioactivity used (Fig. $2 a$ ) coincide with endofacially labelled bands and are probably due to the entry of label into the cell or cell lysis, which resulted in the labelling of highly reactive intracellular sites.

The two 'exofacial' sharp bands (Fig. 2c) had apparent molecular weights of 90000 and 38000 . The former corresponds to band $\alpha$ described by Abbott \& Schachter (1976), and the latter to band $\gamma$. The four broad bands had apparent molecularweight ranges of $130000-150000,95000-115000$, 42000-73000 and 26000-31000. Although the two highest-molecular-weight bands were not observed by Abbott \& Schachter (1976), the other two components correspond to their bands $\beta$ and $\delta$. The front of heavily labelled material in band $\beta$, of apparent molecular-weight range 42000-46000, was also observed by Abbott \& Schachter (1976). Band $\delta$ was not labelled homogeneously and may be a doublet. The labelled band of molecular-weight range $95000-115000$ had the same mobility as band-3 protein, which has been shown to have five thiol groups/molecule, all of which are located on the cytoplasmic side of the membrane (Rao, 1979). If, as we have suggested, MMS does enter the cell via band-3 protein, it is to be expected that some labelling of these groups will occur. This band probably represents $\left.{ }^{[35} \mathrm{S}\right] \mathrm{MMS}$ labelling of a small fraction of the total band-3 protein in the erythrocytes.

\section{Effects of MMS on erythrocyte glucose transport}

The results of two representative experiments are shown in Table 1. At $10 \mathrm{~mm}$ MMS irreversibly

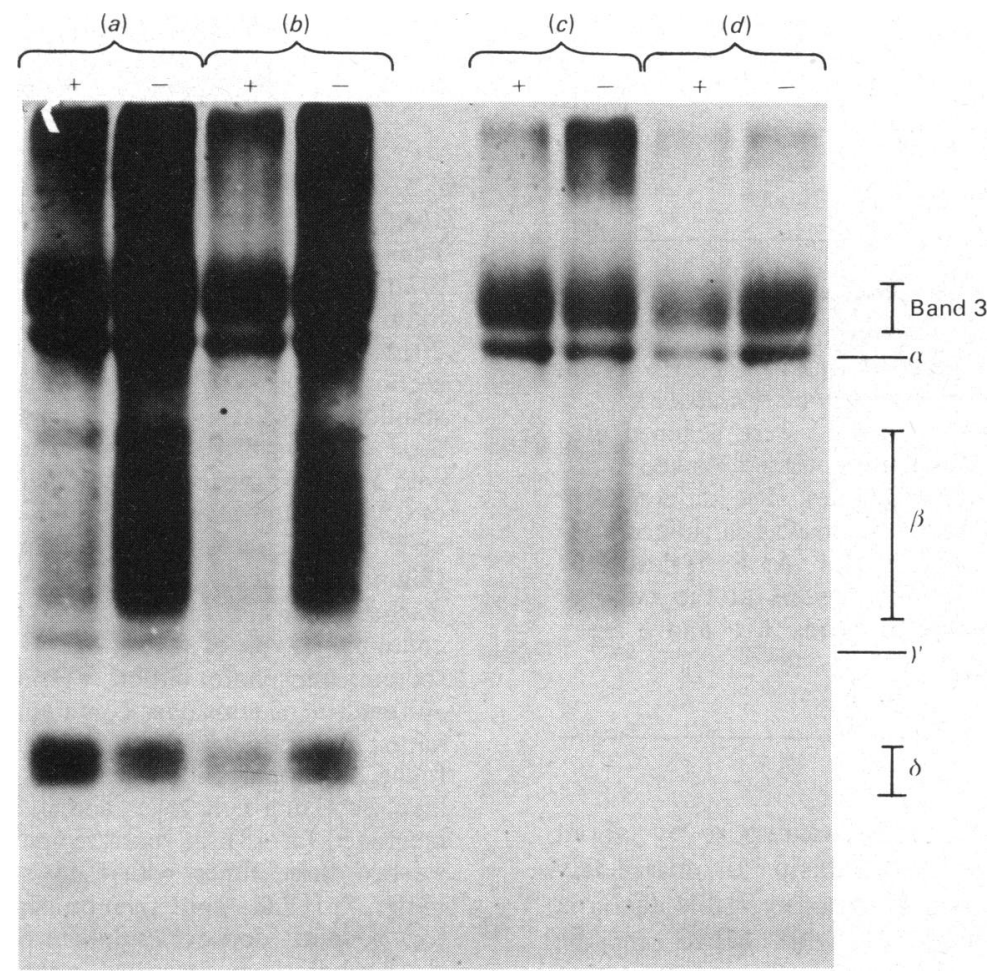

Fig. 3. Labelling of erythrocytes with $\left[{ }^{35} S\right] M M S$ and protection with cytochalasin $b$

Erythrocytes were pretreated with cytochalasin b and/or non-radioactive MMS (first incubation) and subsequently treated with radioactive MMS in the presence or in the absence of cytochalasin $b$ (second incubation) as described in the Methods section. (a) Control with no treatment during first incubation; (b) cytochalasin b treatment during first incubation; (c) non-radioactive MMS and cytochalasin b treatment during first incubation; $(d)$ non-radioactive MMS treatment during first incubation. For each pair of tracks the samples marked + contained cytochalasin $b$ in the second incubation, whereas this was omitted in the samples marked - Gel electrophoresis and radioautography were performed as described in the legend to Fig. 2. 
Table 1. Effect of MMS on erythrocyte glucose-transport rates

Experimental conditions are described in the Methods section. Results are the means \pm S.D. for triplicate determinations.

$\begin{array}{lcc}\text { Pretreatment of erythrocytes } & \text { Expt. 1 } & \text { Expt. 2 } \\ \text { Cytochalasin b } & 763 \pm 127 & 373 \pm 9.3 \\ \text { Cytochalasin b + MMS } & 718 \pm 141 & 393 \pm 60 \\ \text { MMS } & 396 \pm 75 & 229 \pm 71 \\ \text { No additions } & 717 \pm 34 & 411 \pm 56\end{array}$

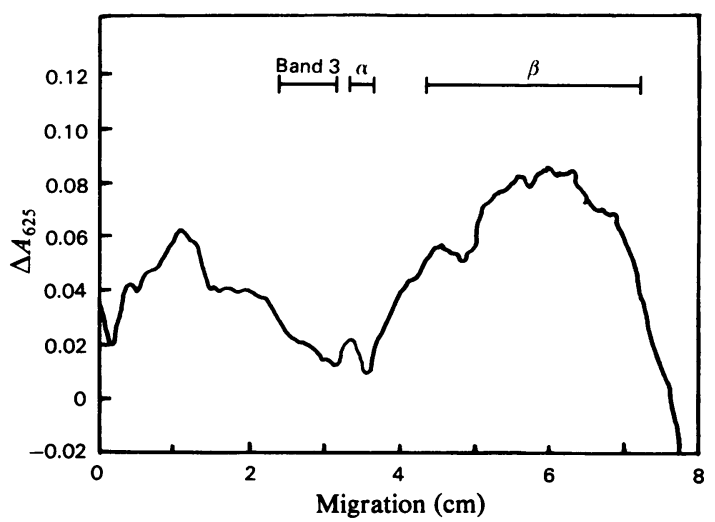

Fig. 4. Differential densitometric scan of radioautographs of erythrocytes labelled with $\left[{ }^{35} S\right] M M S$ in the presence and in the absence of cytochalasin $b$

Tracks $(a)+$ and $(a)-$ in Fig. 3 were scanned at $625 \mathrm{~nm}$ with a Gilford spectrophotometer linked to a Hewlett-Packard 9845 computer. The differential absorbance between the two scans was calculated by using a program written by Dr. A. P. Halestrap (University of Bristol). The regions of the radioautograph corresponding to bands $3, \alpha$ and $\beta$ are marked.

inhibited erythrocyte glucose transport by about $45 \%$, whereas $20 \mu \mathrm{M}$-cytochalasin b completely inhibited glucose transport in a reversible fashion. Incubation of erythrocytes with MMS in the presence of cytochalasin $b$ resulted in the protection of glucose transport against inactivation by MMS. These results are similar to those obtained by Batt $e t$ al. (1976) with glutathione-maleimide.

Fig. 3 shows radioautographs of sodium dodecyl sulphate/polyacrylamide-gel electrophoretograms from an experiment involving the use of $\left.{ }^{35} \mathrm{~S}\right] \mathrm{MMS}$ labelling of erythrocytes together with protection by cytochalasin b. A decrease in the labelling of the

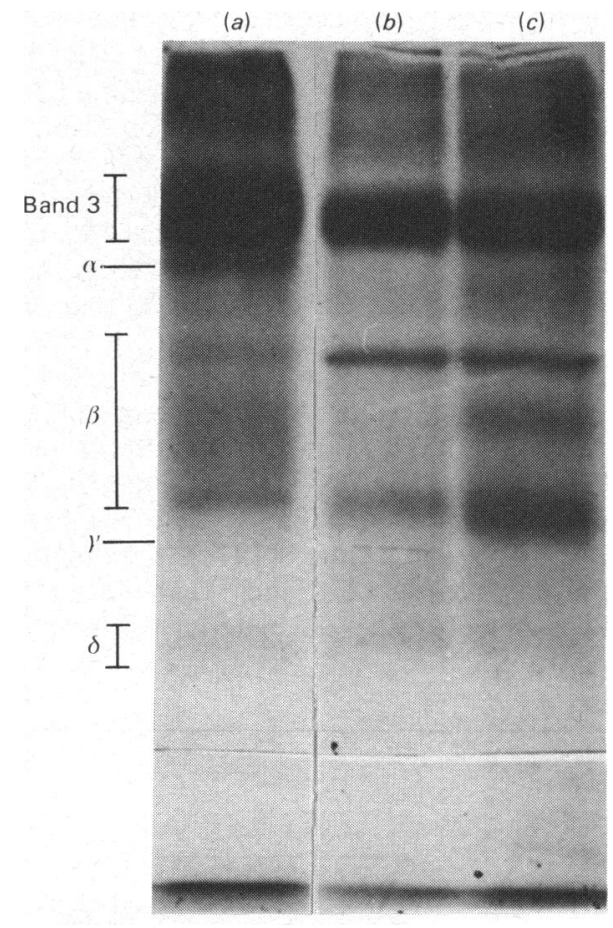

Fig. 5. Effect of endo- $\beta$-galactosidase on the components labelled by $\left[{ }^{35} S\right] M M S$ treatment of intact erythrocytes Packed washed erythrocytes were treated with $\left.3.7 \mathrm{mM}-{ }^{35} \mathrm{~S}\right] \mathrm{MMS}$ (specific radioactivity $480 \mathrm{mCi} /$ $\mathrm{mmol}$ ) in the presence or in the absence of $20 \mu \mathrm{M}$-cytochalasin $\mathrm{b}$, as described in the Methods section. After a washing with 2-mercaptoethanol solution in $0.1 \mathrm{M}$-sodium phosphate buffer, $\mathrm{pH} 8.0$, $50 \mu \mathrm{l}$ portions of packed erythrocytes were treated with $25 \mu \mathrm{g}$ of trypsin (Sigma Chemical Co.) in $50 \mu \mathrm{l}$ of $0.1 \mathrm{M}$-sodium phosphate buffer, $\mathrm{pH} 8.0$, for $30 \mathrm{~min}$ at $37^{\circ} \mathrm{C}$. Then $25 \mu \mathrm{g}$ of soya-bean trypsin inhibitor (Sigma Chemical Co.) was added. The cells were washed twice in $0.15 \mathrm{M}-\mathrm{NaCl}$ and twice in a solution containing $9 \mathrm{vol}$. of $0.15 \mathrm{M}-\mathrm{NaCl}$ to $1 \mathrm{vol}$. of $0.1 \mathrm{M}$ sodium phosphate buffer, pH6.0. Next $50 \mu \mathrm{l}$ of an endo- $\beta$-galactosidase-containing culture supernatant from Bacteroides fragilis (gift from Dr. G. Inglis, Regional Blood Transfusion Centre, Carluke, Scotland, U.K.) was added, and the cells were incubated for $18 \mathrm{~h}$ at room temperature. Cells were washed three times with $0.1 \mathrm{M}$-sodium phosphate buffer, pH8.0, and membranes were prepared for sodium dodecyl sulphate/polyacrylamide-gel electrophoresis as described in the Methods section. Electrophoresis and fluorography were done as described in the legend to Fig. 2. (a) Erythrocytes labelled with $\left[{ }^{35}\right.$ S]MMS in the absence of cytochalasin $b$ and not treated with endo- $\beta$-galactosidase; (b) erythrocytes labelled with [ $\left.{ }^{35} \mathrm{~S}\right] \mathrm{MMS}$ in the presence of cytochalasin $b$ and treated with endo- $\beta$-galactosidase; $(c)$ erythrocytes labelled with ${ }^{[35}$ S]MMS in the absence of cytochalasin $b$ and treated with endo- $\beta$-galactosidase. 
cytochalasin b-binding component would be expected in the cytochalasin b-protected samples. The radioautographs show that the labelling of two of the six exofacially labelled bands is decreased under these conditions. These are the band with apparent molecular weight $130000-150000$ and most of band $\beta$ (but not the region of band $\beta$ migrating at the front with apparent molecular weight 42000 45000). Fig. 4 shows a difference scan of a portion of the radioautograph of tracks $(a)+$ and $(a)-$ of Fig. 3, and demonstrates that band $\beta$ and the band with molecular weight $130000-150000$ both contain differentially labelled material. The highermolecular-weight material $(130000-150000)$ is probably an aggregate of the material in band $\beta$. Endo- $\beta$-galactosidase treatment of erythrocytes decreases the width of both band 3 and band 4.5 by cleaving the oligosaccharide chain (Mueller et al., 1979). Treatment of erythrocytes with trypsin and endo- $\beta$-galactosidase resolved the cytochalasin $b$ protected material into two much sharper bands at molecular weights 40000 and 65000 . Bands $\alpha$ and $\gamma$ disappeared and a new sharp band of apparent molecular weight 72000 was observed (Fig. 5).

The above experiments all used freshly drawn human blood, and show that cytochalasin $b$ decreases labelling in the band-4.5 region. Mullins \& Langdon (1980) have used maltosyl isothiocyanate as an affinity label for the human erythrocyte glucose transporter and reported specific labelling only in the band-3 region with this compound, with freshly drawn erythrocytes. They suggest that the cytochalasin b-binding component observed by others in band 4.5 is a proteolytic fragment of a component of band 3 and that proteolysis occurs either during storage of out-dated blood bank (Batt et al., 1976; Leinhard et al., 1977) or during purification of the polypeptides involved (Kasahara \& Hinkle, 1977). However, Sogin \& Hinkle (1980) have raised an antibody to their purified glucosetransporter preparation and showed that this bound to the band-4.5 region in sodium dodecyl sulphate/ polyacrylamide-gel electrophoretograms of erythrocyte plasma membranes prepared from freshly drawn blood.

The glucose-transport experiments of the present and previous studies strongly suggest that the cytochalasin b-binding protein is part of the glucose-transport system in the erythrocyte. Our results confirm previous reports that this glycoprotein runs as a broad band in the band -4.5 region on sodium dodecyl sulphate/polyacrylamide-gel electrophoretograms. The broadness of this band can be decreased by endo- $\beta$-galactosidase treatment (Mueller et al., 1979), which resolves the material into two peaks at 40000 and 65000 molecular weights.

MMS is a novel impermeant labelling reagent that can be prepared easily and inexpensively at high specific radioactivity. Although at high concentrations the reagent slowly penetrates erythrocytes via the anion-transport protein, and causes some labelling of intracellular sites on this protein, the penetration of the reagent can be diminished by pretreatment of the erythrocytes by 4,4'-diisothiocyanatostilbene-2,2'-disulphonic acid. The erythrocyte has a particularly high anion permeability, and the permeation of the reagent through the anion-transporting systems is likely to be much slower in other cell types.

This work was supported by a grant from the British Diabetic Association.

\section{References}

Abbott, R. E. \& Schachter, D. (1976) J. Biol. Chem. 251, 7176-7183

Baldwin, S. A., Baldwin, J. M., Gorga, F. R. \& Leinhard, G. E. (1979) Biochim. Biophys. Acta 552, 183-188

Batt, E. R., Abbott, R. E. \& Schachter, D. (1976) J. Biol. Chem. 251, 7184-7190

Boxer, D. H., Jenkins, R. E. \& Tanner, M. J. A. (1974) Biochem. J. 137, 531-534

Bretscher, M. S. \& Smith, A. E. (1972) Anal. Biochem. 47, 310-312

Cabantchik, Z. I. \& Rothstein, A. (1974) J. Membr. Biol. 15, 227-278

Chamberlain, J. P. (1979) Anal. Biochem. 98, 132-135

Halestrap, A. P. (1976) Biochem. J. 156, 193-207

Kahlenberg, A. \& Zala, C. A. (1977) J. Supramol. Struct. 7, 287-300

Kasahara, M. \& Hinkle, P. C. (1977) J. Biol. Chem. 252, 7384-7390

Laemmli, U. K. (1970) Nature (London) 227, 680-685

Leinhard, G. E., Gorga, F. R., Orasky, J. E. \& Zoccoli, M. A. (1977) Biochemistry 16, 4921-4926

Levine, M. \& Stein, W. D. (1966) Biochim. Biophys. Acta 127, 179-193

Mueller, T. J., Li, Y.-T. \& Morrison, M. (1979) J. Biol. Chem. 254, 8103-8106

Mullins, R. E. \& Langdon, R. G. (1980) Biochemistry 19, 1205-1212

Rao, A. (1979) J. Biol. Chem. 254, 3503-3511

Rich, D. H., Gesellchen, P. D., Tong, A., Cheung, A. \& Buckner, C. K. (1975) J. Med. Chem. 18, 1004-1010

Sogin, D. C. \& Hinkle, P. C. (1980) Proc. Natl. Acad. Sci. U.S.A. 77, 5725-5729

Steck, T. L. (1974) J. Cell Biol. 62, 1-19 